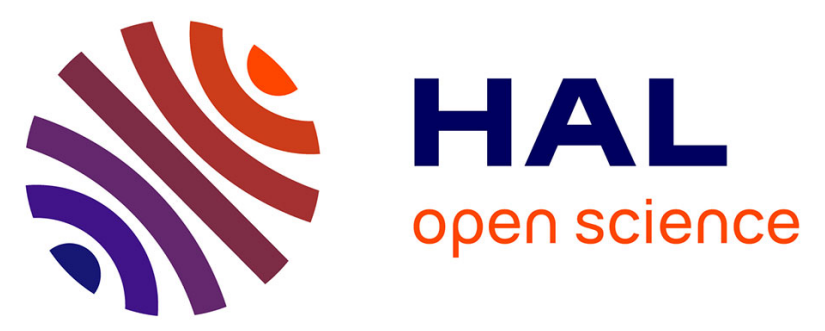

\title{
Aircraft time-2D longitudinal guidance based on spatial inversion of flight dynamics
}

\author{
Hakim Bouadi, Felix Mora-Camino, Daniel Choukroun
}

\section{To cite this version:}

Hakim Bouadi, Felix Mora-Camino, Daniel Choukroun. Aircraft time-2D longitudinal guidance based on spatial inversion of flight dynamics. DASC 2012, 31st IEEE/AIAA Digital Avionics Systems Conference, Oct 2012, Williamsburg, United States. pp 3C4-1 - 3C4-14, 10.1109/DASC.2012.6382313 . hal-00938908

\section{HAL Id: hal-00938908 \\ https://hal-enac.archives-ouvertes.fr/hal-00938908}

Submitted on 19 Jun 2014

HAL is a multi-disciplinary open access archive for the deposit and dissemination of scientific research documents, whether they are published or not. The documents may come from teaching and research institutions in France or abroad, or from public or private research centers.
L'archive ouverte pluridisciplinaire HAL, est destinée au dépôt et à la diffusion de documents scientifiques de niveau recherche, publiés ou non, émanant des établissements d'enseignement et de recherche français ou étrangers, des laboratoires publics ou privés. 


\title{
AIRCRAFT TIME-2D LONGITUDINAL GUIDANCE BASED ON SPATIAL INVERSION OF FLIGHT DYNAMICS
}

\author{
Hakim Bouadi, F.Mora-Camino, MAIAA/ENAC, Toulouse, France \\ Daniel Choukroun, Delft university, Amsterdam, Netherlands
}

\begin{abstract}
With the growth of civil aviation traffic capacity, safety and environmental considerations urge today for the development of guidance systems with improved accuracy for spatial and temporal trajectory tracking. This should induce increased capacity by allowing safe operations at minimum separation standards. Also, at take-off and landing, trajectory dispersion should be reduced resulting in controlled noise impacts on airport surrounding communities. Current civil aviation guidance systems operate with real time corrective actions to maintain the aircraft trajectory as close as possible to the planned trajectory. In this paper, we consider the problems of designing new longitudinal guidance control laws for an autopilot so that accurate vertical tracking and overfly time are better insured. Instead of using time as the independent variable to describe the guidance dynamics of the aircraft, we adopt distance to land, which can be considered today to be available online with acceptable accuracy and availability. A new representation of aircraft longitudinal guidance dynamics is developed according to this spatial variable. Then a nonlinear inverse control law based-on this new proposed spatial representation of guidance dynamics is established to make the aircraft follow accurately a vertical profile and a desired airspeed. The desired airspeed is then regulated to make the aircraft overfly different waypoints according to a planned timetable. Then simulations experiments with different wind conditions are performed for a transportation aircraft performing a general descent approach for landing. These simulation results are compared with those obtained from a classical time-based guidance control law.
\end{abstract}

\section{Introduction}

World air transportation traffic has known a sustained increase over the last decades leading to airspace near saturation in large areas of developed and emerging countries. For example, today up to
27,000 flights cross European airspace every day while the number of passengers is expected to double by 2020. Then safety and environmental considerations urge today for the development of new guidance systems with improved accuracy for spatial and temporal trajectory tracking. Available infrastructure of current ATM (Air Traffic Management) will no longer be able to stand this growing demand unless breakthrough improvements are made.

In the future air traffic management environment defined by SESAR (Single European Sky ATM Research) and NextGen (Next Generation Air Transportation System) projects, two main objectives are targeted, strategic data link services for sharing of information and negotiation of planning constraints between ATC (Air Traffic Control) and the aircraft in order to ensure planning consistency and the use of the 4D aircraft trajectory information in the flight management system for ATC operations [1], [2], [3]. This means that in addition to following the trajectory cleared by ATC, aircraft will progress in four dimensions, sharing accurate airborne predictions with the ground systems, and being able to meet time constraints at specific waypoints with high precision when the traffic density requires it [4], [5], [6], [7]. This will allow better separation and sequencing of traffic flows while green climb/descent trajectories will be feasible in terminal areas.

Current civil aviation guidance systems operate with real time corrective actions to maintain the aircraft trajectory as close as possible to the planned trajectory or to follow timely ATC tactical demands based either on spatial or temporal considerations [8], [9]. While wind remains one of the main causes of guidance errors [10], [11], [12], these news solicitations by ATC are attended with relative efficiency by current airborne guidance systems. However, these guidance errors are detected for correction by navigation systems whose accuracy has known large improvements in the last decade with the hybridization of inertial units with satellite information. Nevertheless, until today vertical 
guidance remains problematic [13], [14] and corresponding covariance errors [15] are still large considering the time-based control laws which are applied by flight guidance systems [12], [16].

In this paper, we consider the problem of designing new vertical guidance control laws for an autopilot so that accurate vertical tracking and overfly time are better insured. Instead of using time as the independent variable to describe the guidance dynamics of the aircraft, we adopt distance to land, which can be considered today to be available online with acceptable accuracy and availability. A new representation of aircraft vertical guidance dynamics is developed according to this spatial variable. Then a nonlinear inverse control law based-on this new proposed spatial representation of guidance dynamics is established to make the aircraft follow accurately a vertical profile and a desired airspeed [17], [18]. The desired airspeed is then regulated to meet two main constraints related to the stall speed and the maximum operating speed and to make the aircraft overfly different waypoints according to a planned time-table.

Then simulations experiments with different wind conditions are performed for a transportation aircraft performing a general descent approach for landing. These simulation results are compared with those obtained from a classical time-based guidance control law. It appears that with this new guidance approach, vertical 2D plus time guidance can be achieved more accurately with standard spatial tracking convergence in height and time.

\section{Aircraft Longitudinal Flight Dynamics}

The motion of an approach/descent transportation aircraft along a landing trajectory will be referenced with respect to a RRF (Runway Reference Frame) where its origin is located at the runway entrance as shown in Figure 1.

The vertical plane components of the inertial speed are such as:

$$
\begin{gathered}
\dot{x}=-V_{\text {air }} \cos \gamma_{\text {air }}+w_{x} \\
\dot{z}=V_{\text {air }} \sin \gamma_{\text {air }}+w_{z}
\end{gathered}
$$

and inversely:

$$
V_{\text {air }}=\sqrt{\left(\dot{x}-w_{x}\right)^{2}+\left(\dot{z}-w_{z}\right)^{2}}
$$

$$
\gamma_{\text {air }}=-\operatorname{arctg}\left(\frac{\dot{z}-w_{z}}{\dot{x}-w_{x}}\right)
$$

where $x$ and $z$ are the vertical plane coordinates of the aircraft centre of gravity in the runway reference system, $V_{\text {air }}$ is the airspeed modulus, $\gamma_{\text {air }}$ is the airspeed path angle, $w_{x}$ and $w_{z}$ are the wind components in the RRF.

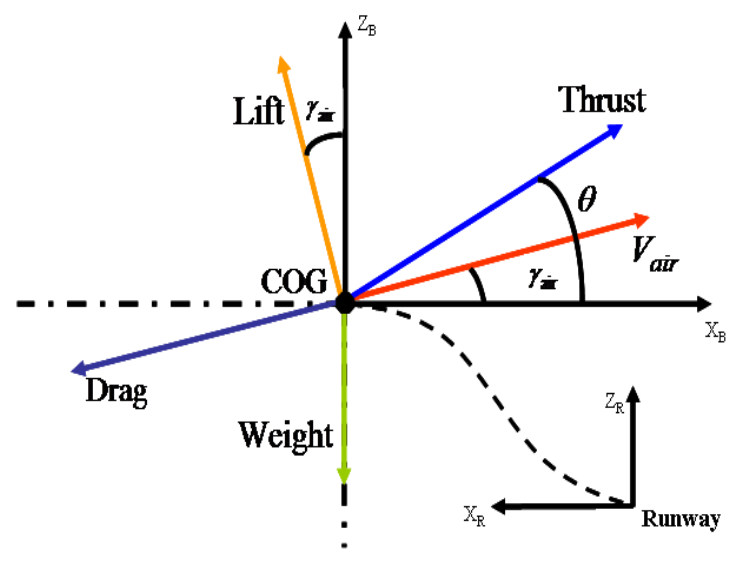

Figure 1. Aircraft Forces

Adopting classical assumptions such as the RRF being an inertial frame, local flatness of the Earth, constant aircraft mass, the translational acceleration equations can be written as:

$$
\begin{aligned}
m \ddot{x}= & -T \cos \theta+D\left(z, V_{\text {air }}, \alpha\right) \cos \gamma_{\text {air }} \\
& +L\left(z, V_{\text {air }}, \alpha\right) \sin \gamma_{\text {air }} \\
m \ddot{z}= & T \sin \theta-D\left(z, V_{\text {air }}, \alpha\right) \sin \gamma_{\text {air }} \\
& +L\left(z, V_{\text {air }}, \alpha\right) \cos \gamma_{\text {air }}-m g
\end{aligned}
$$

$T, D$ and $L$ are respectively the thrust, drag and lift forces. The lift and drag forces are given by:

$$
\begin{aligned}
& L=\frac{1}{2} \rho(z) V_{\text {air }}^{2} S C_{L} \\
& D=\frac{1}{2} \rho(z) V_{\text {air }}^{2} S C_{D}
\end{aligned}
$$

where $\rho(z), S, C_{L}$ and $C_{D}$ represent the air density with respect to the altitude, the wing surface area, the lift and drag coefficients, respectively.

$$
\begin{gathered}
C_{L}=C_{L_{0}}+C_{L_{\alpha}} \alpha \\
C_{D}=C_{0}+C_{1} \alpha+C_{2} \alpha^{2}
\end{gathered}
$$


According to the polar model, the aerodynamic parameters $C_{0}, C_{1}$ and $C_{2}$ are such as:

$$
\begin{gathered}
C_{0}=C_{D_{0}}+k C_{L_{0}}^{2} \\
C_{1}=2 k C_{L_{0}} C_{L_{\alpha}} \\
C_{2}=k C_{L_{\alpha}}^{2}
\end{gathered}
$$

Assuming first order dynamics with time constant $\tau$ for the engines, we get between commanded thrust $T_{C}$ and effective thrust $T$ the following relation:

$$
\dot{T}=\frac{1}{\tau}\left(T_{C}-T\right)
$$

Under the above assumptions, the pitch rate is given by:

$$
\dot{\theta}=q
$$

Equations (3a) and (3b) can be rewritten in the aircraft airspeed frame such as:

$$
\begin{gathered}
\dot{V}_{\text {air }}=\frac{1}{m}\left[\begin{array}{l}
T \cos \alpha-D\left(z, V_{\text {air }}, \alpha\right)-m g \sin \gamma_{\text {air }} \\
+m\left(\dot{w}_{x} \cos \gamma_{\text {air }}-\dot{w}_{z} \sin \gamma_{\text {air }}\right)
\end{array}\right] \\
\dot{\gamma}_{\text {air }}=\frac{1}{m V_{\text {air }}}\left[\begin{array}{l}
T \sin \alpha+L\left(z, V_{\text {air }}, \alpha\right)-m g \cos \gamma_{\text {air }} \\
-m\left(\dot{w}_{x} \sin \gamma_{\text {air }}+\dot{w}_{z} \cos \gamma_{\text {air }}\right)
\end{array}\right]
\end{gathered}
$$

where $\alpha$ denotes the angle of attack with:

$$
\alpha=\theta-\gamma_{\text {air }}
$$

\section{Space Referenced Longitudinal Flight Dynamics}

Considering that during an approach/descent manoeuvre without holdings the distance-to-land time function $x(t)$ is invertible it is possible to express during these maneuvers all the flight variables with respect to $x$ and its derivatives instead of time.

Here ground speed at position $x$ and time $t$ is given by:

$$
V_{G}=\dot{x}=-V_{\text {air }} \cos \gamma_{\text {air }}+w_{x}
$$

Here the following notation is adopted: $\frac{d^{k} *}{d x^{k}}=*^{[k]}$ and the guidance dynamics can be written as:

$$
\begin{gathered}
z^{[1]}=\frac{d z}{d x}=\frac{d z}{d t} \frac{d t}{d x}=\frac{V_{\text {air }} \sin \gamma_{\text {air }}+w_{z}}{V_{G}} \\
\theta^{[1]}=\frac{q}{V_{G}} \\
T^{[1]}=\frac{T_{C}-T}{\tau V_{G}} \\
V_{\text {air }}^{[1]}=\frac{1}{m V_{G}}\left[\begin{array}{l}
T \cos \alpha-D\left(z, V_{\text {air }}, \alpha\right)-m g \sin \gamma_{\text {air }} \\
+m\left(\dot{w}_{x} \cos \gamma_{\text {air }}-\dot{w}_{z} \sin \gamma_{\text {air }}\right)
\end{array}\right] \\
\gamma_{\text {air }}^{[1]}=\frac{1}{m V_{\text {air }} V_{G}}\left[\begin{array}{l}
T \sin \alpha+L\left(z, V_{\text {air }}, \alpha\right)-m g \cos \gamma_{\text {air }} \\
-m\left(\dot{w}_{x} \sin \gamma_{\text {air }}+\dot{w}_{z} \cos \gamma_{\text {air }}\right)
\end{array}\right] \\
\text { then, with respect to } z^{[2]} \text { we get: } \\
z^{[2]}=\frac{1}{V_{G}^{2}}\left[\begin{array}{l}
\left(V_{\text {air }}^{[1]} \sin \gamma_{\text {air }}+V_{\text {air }} \gamma_{\text {air }}^{[1]} \cos \gamma_{\text {air }}+w_{z}^{[1]}\right) \\
-\left(V_{\text {air }} \sin \gamma_{\text {air }}+w_{z}\right) V_{G}^{[1]}
\end{array}\right]
\end{gathered}
$$

The independent control inputs to the above flight dynamics are chosen to be $q$ and $T_{C}$ while $w_{x}$ and $w_{z}$ are perturbation inputs. Equivalent controls $q$ and $T_{C}$ are respectively the result of pitch control and the result of the engine thrust setting.

Note that, the space-based state equation related to the pitch is such as:

$$
q^{[1]}=\frac{d q}{d t} \frac{d t}{d x}=\frac{\dot{q}}{V_{G}}=\frac{M}{I_{y} V_{G}}
$$

where $M, I_{y}$ denote respectively the pitch moment and inertia moment according to the aircraft lateral axis:

$$
M=\frac{1}{2} \rho V_{\text {air }}^{2} S \bar{c}\left(C_{m_{0}}+C_{m_{\alpha}} \alpha+C_{m_{q}} \frac{\bar{q}}{2 V_{\text {air }}}+C_{m_{\delta_{e}}} \delta_{e}\right)
$$

with $\bar{c}$ and $\delta_{e}$ represent the mean chord line and the elevator deflection, respectively.

\section{Vertical Trajectory Tracking Control Objectives}

Here main guidance objectives can be twofold: 
- To follow accurately a space-referenced vertical profile $z_{d}(x)$ in accordance with economic and environmental constraints,

- To respect a desired time table $t_{d}(x)$ for its progress towards the runway in accordance with air traffic management considerations,

while speed constraints must be satisfied.

Trying to meet directly the second objective in presence of wind can lead to hazardous situations with respect to airspeed limits. So this objective is expressed through the on-line definition of a desired airspeed to be followed. Here, it is supposed that online estimates of wind parameters are available [15].

From the desired time table $t_{d}(x)$, we get a desired ground speed $V_{G_{d}}(x)$ :

$$
V_{G_{d}}(x)=1 /\left(d t_{d}(x) / d x\right)
$$

then, tacking into account an estimate of the longitudinal component of wind speed, a spacereferenced desired airspeed $V_{\text {air }}(x)$ can be defined:

- For low speeds, a minimum margin with respect to the stall speed at the current desired level:

$$
V_{\text {air }}(x)=\operatorname{Max}\left\{V_{S}\left(z_{d}(x)\right)+\Delta V_{\min }, V_{G_{d}}(x)-\hat{w}_{x}(x)\right\}
$$

where $V_{S}, \Delta V_{\min }$ and $\hat{w}_{x}$ are the stall speed, the minimum margin speed and the estimate of the horizontal wind speed, respectively.

- For high speeds, an airspeed less than the maximum operating speed at the current desired level:

$$
V_{\text {air }}(x)=\operatorname{Min}\left\{V_{\mathrm{MO}}\left(z_{d}(x)\right), V_{G_{d}}(x)-\hat{w}_{x}(x)\right\}
$$

where $V_{\mathrm{MO}}$ denotes the maximum operating speed.

- In all other cases:

$$
V_{\text {air }}(x)=V_{G_{d}}(x)-\hat{w}_{x}(x)
$$

\section{Space-Based Against Time-Based Reference Trajectories}

In the literature, countless control techniques have been designed for aircraft trajectory tracking using time as the independent variable [23] while quite nothing has been published until recently with space as the independent variable [18]. However, many ATC solicitations to aircraft guidance can be considered to introduce space based constraints (time separation at a given waypoint, continuous descent approaches, time metered approaches for optimal use of runways, etc). The use of classical time based guidance systems in these situations appears to contribute to the Flight Technical Error (FTE) of the guidance system. Then, to display the interest for this new approach, in this section it is shown how for general aircraft operations linear decoupled space and time referenced guidance dynamics are not equivalent.

It has been shown in [18] that nonlinear inverse control techniques can be used to make the guidance variable $z$ and $V_{\text {air }}$ to satisfy decoupled linear spatial dynamics such as:

$$
\begin{gathered}
\sum_{k=0}^{K_{V}} a_{k}^{V}\left(V_{a i r}-V_{a i r_{d}}\right)^{[k]}=0 \\
\sum_{k=0}^{K_{z}} a_{k}^{z}\left(z-z_{d}\right)^{[k]}=0
\end{gathered}
$$

where the corresponding characteristic polynomials are chosen to be asymptotically stable with adequate transients and response times. Here $K_{z}$ and $K_{V}$ are related with the relative degrees of outputs $z$ and $V_{\text {air }}$ [24].

According to derivation rules for composed functions, we get:

$$
\begin{gathered}
\xi_{z}^{[1]}=\frac{\dot{\xi}_{z}}{V_{G}} \\
\xi_{z}^{[2]}=\frac{1}{V_{G}^{2}}\left(\ddot{\xi}_{z}-\frac{\dot{\xi}_{z} \dot{V}_{G}}{V_{G}}\right) \\
\xi_{z}^{[3]}=\frac{1}{V_{G}^{3}}\left[\dddot{\xi}_{z}-3 \ddot{\xi}_{z} \frac{\dot{V}_{G}}{V_{G}}+\dot{\xi}_{z}\left(3 \frac{\dot{V}_{G}^{2}}{V_{G}^{2}}-\frac{\ddot{V}_{G}}{V_{G}}\right)\right]
\end{gathered}
$$

and

$$
\xi_{V_{\text {air }}^{[1]}}^{[1]}=\frac{\dot{\xi}_{V_{\text {air }}}}{V_{G}}
$$




$$
\xi_{V_{\text {air }}^{[2]}}^{[2]} \frac{1}{V_{G}^{2}}\left(\ddot{\xi}_{V_{\text {air }}}-\frac{\dot{\xi}_{V_{a i r}} \dot{V}_{G}}{V_{G}}\right)
$$

with $\xi_{z}(x)$ and $\xi_{V_{a i r}}(x)$ be the tracking errors related to the desired altitude $z_{d}(x)$ and desired airspeed profile $V_{\text {air }}(x)$, respectively:

$$
\begin{gathered}
\xi_{z}(x)=z(x)-z_{d}(x) \\
\xi_{V_{a i r}}(x)=V_{\text {air }}(x)-V_{a i r_{d}}(x)
\end{gathered}
$$

and

$$
\begin{aligned}
& V_{G}(x(t))= w_{x}(x(t))-\left[V_{\text {air }}(x(t))+\xi_{V_{\text {air }}}(x(t))\right] \times \\
& \sqrt{1-\left[\frac{\dot{z}_{d}(x(t))+\dot{\xi}_{z}(x(t))-w_{z}(x(t))}{V_{\text {air }}(x(t))+\xi_{V_{\text {air }}}(x(t))}\right]^{2}}
\end{aligned}
$$

Then equations (20a) and (20b) can be rewritten as follows:

$$
\begin{gathered}
\xi_{V_{a i r}}^{[2]}(x)+k_{1 v} \xi_{V_{\text {air }}}^{[1]}(x)+k_{2 v} \xi_{V_{\text {air }}}(x)=0 \\
\xi_{z}^{[3]}(x)+k_{1 z} \xi_{z}^{[2]}(x)+k_{2 z} \xi_{z}^{[1]}(x)+k_{3 z} \xi_{z}(x)=0
\end{gathered}
$$

where $k_{1 v}, k_{2 v}, k_{1 z}, k_{2 z}$ and $k_{3 z}$ are real parameters such as the roots of $s^{2}+k_{1 v} s+k_{2 v}$ and $s^{3}+k_{1 z} s^{2}+k_{2 z} s+k_{3 z}$ produce adequate tracking error dynamics (convergence without oscillation in accordance with a given space segment) with $s$ denotes the Laplace variable.

It appears that when replacing in equations (25a) and (25b) the space derivatives of the outputs by the expressions given by (21a) to (22b), we get nonlinear coupled time dynamics for the altitude and the airspeed errors. Only in the case of a constant ground speed where the space and temporal derivatives are related by:

$$
\begin{aligned}
& \xi_{z}^{[k]}=\frac{\xi_{z}^{(k)}}{V_{G}^{k}} \\
& \xi_{V_{\text {air }}}^{[k]}=\frac{\xi_{V_{\text {air }}}^{(k)}}{V_{G}^{k}}
\end{aligned}
$$

we get equivalent linear decoupled time dynamics given by:

$$
\dddot{\xi}_{z}+k_{1 z} V_{G} \ddot{\xi}_{z}+k_{2 z} V_{G}^{2} \dot{\xi}_{z}+k_{3 z} V_{G}^{3} \xi_{z}=0
$$

$$
\ddot{\xi}_{V_{\text {air }}}+k_{1 v} V_{G} \dot{\xi}_{V_{\text {air }}}+k_{2 v} V_{G}^{2} \xi_{V_{\text {air }}}=0
$$

This case corresponds to a no wind situation where airspeed is maintained constant.

In the case where $\dot{V}_{G}$ remains constant over a time (space) span, equations (27a) and (27b) become:

$$
\begin{aligned}
& \dddot{\xi}_{z}+\left(k_{1 z} V_{G}-3 \frac{\dot{V}_{G}}{V_{G}}\right) \ddot{\xi}_{z}+\left(k_{2 z} V_{G}^{2}-k_{1 z} \dot{V}_{G}+3 \frac{\dot{V}_{G}^{2}}{V_{G}^{2}}\right) \dot{\xi}_{z} \\
& +k_{3 z} V_{G}^{3} \xi_{z}=0
\end{aligned}
$$

$$
\ddot{\xi}_{V_{\text {air }}}+\left(k_{1 v} V_{G}-\frac{\dot{V}_{G}}{V_{G}}\right) \dot{\xi}_{V_{\text {air }}}+k_{2 v} V_{G}^{2} \xi_{V_{\text {air }}}=0
$$

Here $V_{G}$ is such as:

$$
V_{G}(t)=V_{G}\left(t_{0}\right)+\dot{V}_{G} \cdot\left(t-t_{0}\right)
$$

then the above decoupled dynamics have time variant parameters and the predictivity (time of response) of these dynamics is lost. It can be however shown that if $\dot{V}_{G}$ is very small with respect to $V_{G}$, these dynamics remain stable.

Then the adoption of a time based reference trajectories are of interest when guidance requirements can be better expressed with respect to space (especially when time constraints at specific waypoints are considered). Then it appears that adopting in this case a space based trajectory tracking technique should avoid this source of error.

\section{Space-Based NLI Tracking Control}

In this section the space-based nonlinear inverse control technique introduced in [18] to perform aircraft trajectory tracking is displayed. The trajectory output variables equations can be written under an affine form with respect to the inputs $q$ and $T_{C}:$

$$
\begin{array}{r}
V_{\text {air }}^{[2]}=\frac{1}{V_{G}^{2}}\left[\begin{array}{l}
A_{V}\left(z, \alpha, V_{\text {air }}, T, W\right) \\
+B_{V_{q}}\left(z, \alpha, V_{\text {air }}, T, W\right) q \\
+B_{V_{T}}\left(z, \alpha, V_{\text {air }}, T, W\right) T_{C}
\end{array}\right] \\
z^{[3]}=\frac{1}{V_{G}^{2}}\left[\begin{array}{l}
A_{z}\left(z, \alpha, V_{\text {air }}, T, W\right) \\
+B_{z_{q}}\left(z, \alpha, V_{\text {air }}, T, W\right) q \\
+B_{z_{T}}\left(z, \alpha, V_{\text {air }}, T, W\right) T_{C}
\end{array}\right]
\end{array}
$$


where $W$ represents the parameters $w_{x}, w_{z}, \dot{w}_{x}, \dot{w}_{z}$ and $\ddot{w}_{x}, \ddot{w}_{z}$ which can be expressed successively .

Since the $B_{i}$ terms shown below are in general different from zero, the spatial relative degree of $V_{\text {air }}$ and $z$ are equal respectively to 1 and 2 , then in this case there are no internal dynamics to worry about.

The rather complex expressions of components $A_{V}, B_{V_{q}}, B_{V_{T}}$ and $A_{z}, B_{z_{q}}, B_{z_{T}}$ in (30a) and (30b) are detailed in [17].

In the above equations the temporal derivatives $\dot{u}$ and $\ddot{u}$ with $u \in\left\{x, z, V_{\text {air }}, \gamma_{\text {air }}, w_{x}, w_{z}\right\}$ are related with the spatial derivatives of $u$ by:

$$
\begin{gathered}
\dot{u}=u^{[1]} V_{G} \\
\ddot{u}=u^{[2]} V_{G}^{2}+u^{[1]} V_{G}^{[1]} V_{G}
\end{gathered}
$$

The desired vertical trajectory $z_{d}(x)$ is supposed to be a smooth function of $x$ (in the considered application $x$ is the distance to touchdown) while considering expressions (17), (18) and (19) $V_{\text {air }_{d}}$ is supposed to be a piecewise smooth function of $x$.

Since in general flight conditions the control matrix given by:

$$
\left(\begin{array}{ll}
B_{z_{q}} & B_{z_{T}} \\
B_{V_{q}} & B_{V_{T}}
\end{array}\right)
$$

is invertible [18], it is possible to perform the dynamic inversion to get effective trajectory tracking control laws [22], [23]. So we get:

$$
\left(\begin{array}{c}
q \\
T_{C}
\end{array}\right)=\left(\begin{array}{ll}
B_{z_{q}} & B_{z_{T}} \\
B_{V_{q}} & B_{V_{T}}
\end{array}\right)^{-1} \times\left(\begin{array}{c}
V_{G}^{2} D_{z}(x)-A_{z} \\
V_{G}^{2} D_{V_{a i r}}(x)-A_{V}
\end{array}\right)
$$

with:

$$
\begin{gathered}
D_{z}(x)=z_{d}^{[3]}(x)+k_{1 z} \xi_{z}^{[2]}(x)+k_{2 z} \xi_{z}^{[1]}(x)+k_{3 z} \xi_{z}(x) \\
D_{V_{\text {air }}}(x)=V_{\text {air }}^{[2]}(x)+k_{1 v} \xi_{V_{\text {air }}}^{[1]}(x)+k_{2 v} \xi_{V_{\text {air }}}(x)
\end{gathered}
$$

Observe here that while the successive spatial derivatives of desired outputs $z_{d}(x)$ and $V_{\text {air }}(x)$ can be directly computed, the successive spatial derivatives of actual outputs $z(x)$ and $V_{\text {air }}(x)$ in (34a) and (34b) can be computed from relations (12a), (12d) and (13) where the wind parameters must be replaced by their estimates.
In order to make the aircraft overfly different waypoints according to a planned time-table $t_{d}(x)$, a simple outer-loop PID controller is introduced. Desired airspeed is computed and regulated to meet constraints related basically to the desired ground speed $V_{G_{d}}(x)$, the minimum allowable speed and the maximum operating speed. Desired ground speed is defined based on the reference time-table $t_{d}(x)$ according to the equation (16). Then the PID speed versus space controller is expressed as:

$$
u_{t}(x)=K_{p} e_{t}(x)+K_{d} \frac{d e_{t}}{d x}(x)+K_{i} \int_{x_{\text {init }}}^{x_{f}} e_{t}(\varpi) d \varpi
$$

where:

$$
e_{t}(x)=t(x)-t_{d}(x)
$$

\section{Adopted Wind Model}

In this study, longitudinal wind is expressed here according to [20] and [21] as:

$$
\begin{gathered}
W_{z}(x, z, t)=w_{z}=\delta_{z}\left(V_{\text {air }}, z, t\right) \\
W_{x}(x, z, t)=w_{x}=W_{x}(z)+\delta_{x}\left(V_{\text {air }}, z, t\right)
\end{gathered}
$$

where $W_{x}(z)$ and $\delta_{x, z}\left(V_{\text {air }}, z, t\right)$ represent the deterministic and stochastic components of the considered wind, respectively.

The deterministic horizontal wind speed component is expressed as:

$$
\begin{gathered}
W_{x}(z)=W_{0}(z) \ln \left(\frac{z}{z_{0}}\right) \\
W_{0}(z)=W_{0}^{*} \cos \left(\omega z+\varphi_{0}\right)
\end{gathered}
$$

where $\omega$ and $W_{0}^{*}$ denote the circular space frequency and magnitude of the considered wind component.

The stochastic wind components adopt Dryden spectrum model [22] generated from two normalized white Gaussian noise processes through linear filters such as:

$$
H_{\delta_{x}}(s)=\frac{\sigma_{x} \sqrt{2 L_{x x} V_{a i r}}}{V_{a i r}+L_{x x} s}
$$

and 


$$
H_{\delta_{z}}(s)=\sigma_{z} \sqrt{\frac{L_{z z}}{V_{\text {air }}}}\left[\frac{1+\sqrt{3} \frac{L_{z z}}{V_{\text {air }}} s}{\left(1+\frac{L_{z z}}{V_{\text {air }}} s\right)^{2}}\right]
$$

Here $L_{x x}$ and $L_{z z}$ are shape parameters (turbulence lengths) such as:

- For $z \leq 305 \mathrm{~m}$

$$
\begin{gathered}
L_{x x}=\frac{z}{(0.177+0.0027 z)^{1.2}} \\
L_{z z}=z
\end{gathered}
$$

- For $z>305 \mathrm{~m}$

$$
L_{x x}=L_{z z}=305 \mathrm{~m}
$$

where $\sigma_{x}$ and $\sigma_{z}$ represent standard deviations of independent processes such as:

$$
\sigma_{z}=0.1 W_{20}
$$

and $W_{20}$ is the horizontal wind speed at $20 \mathrm{ft}$ above ground level.

- For $z \leq 305 \mathrm{~m}$

$$
\sigma_{x}=\frac{\sigma_{z}}{(0.177+0.0027 z)^{0.4}}
$$

- For $z>305 \mathrm{~m}$

$$
\sigma_{x}=\sigma_{z}
$$

Time and spatial derivatives of the wind components are then given by:

$$
\dot{w}_{x}=W_{x x} \dot{x}+W_{x z} \dot{z}+W_{x t}
$$

With:

$$
W_{x x}=\frac{\partial W_{x}}{\partial x}, W_{x z}=\frac{\partial W_{x}}{\partial z}, W_{x t}=\frac{\partial W_{x}}{\partial t}
$$

and

$$
\dot{w}_{z}=W_{z x} \dot{x}+W_{z z} \dot{z}+W_{z t}
$$

With:

$$
W_{z x}=\frac{\partial W_{z}}{\partial x}, W_{z z}=\frac{\partial W_{z}}{\partial z}, W_{z t}=\frac{\partial W_{z}}{\partial t}
$$

\section{Simulation Study}

The proposed guidance approach is illustrated using the Research Civil Aircraft Model (RCAM) which has the characteristics of a wide body transportation aircraft [24] with a maximum allowable landing mass of about 125 tons with a nominal landing speed of $68 \mathrm{~m} / \mathrm{s}$. There, the control signals are submitted to rate limits and saturations as follows:

$$
\begin{aligned}
-15 \frac{\pi}{180} \mathrm{rad} / \mathrm{s} & \leq \dot{\delta}_{e} \leq 15 \frac{\pi}{180} \mathrm{rad} / \mathrm{s} \\
-25 \frac{\pi}{180} \mathrm{rad} & \leq \delta_{e} \leq 10 \frac{\pi}{180} \mathrm{rad} \\
-1.6 \frac{\pi}{180} \mathrm{rad} / \mathrm{s} & \leq \dot{T}_{C} \leq 1.6 \frac{\pi}{180} \mathrm{rad} / \mathrm{s} \\
0.5 \frac{\pi}{180} \mathrm{rad} & \leq T_{C} \leq 10 \frac{\pi}{180} \mathrm{rad}
\end{aligned}
$$

While the minimum allowable speed is $1.23 \mathrm{~V}_{\text {stall }}$ with $V_{\text {stall }}=51.8 \mathrm{~m} / \mathrm{s}$ and the angle of attack is limited to the domain $\left[-11.5^{\circ}, 18^{\circ}\right\rfloor$ where $\alpha_{\text {stall }}=18^{\circ}$.

\section{Simulation results in no wind condition}

In a no wind condition, Figure $2 \mathrm{a}$ and Figure $2 \mathrm{~b}$ display respectively altitude tracking performances resulting from time NLI and space NLI guidance schemes. While Figure $3 \mathrm{a}$ and Figure $3 \mathrm{~b}$ provide closer views of altitude and tracking performance during initial transients, it appears clearly that in both cases the spatial NLI trajectory tracking technique provides better results: the spatial span for convergence towards the desired trajectories is shortened by about $2000 \mathrm{~m}$ while convergence is performed with reduced oscillations. Figure $4 \mathrm{a}$ and Figure $4 \mathrm{~b}$ display airspeed tracking performances by time NLI and space NLI guidance schemes, respectively when the aircraft is initially late according to the planned time table. It appears clearly that the aircraft increases its airspeed to the maximum operating speed during $12000 \mathrm{~m}$ until it catches up its delay as it is also shown in Figure 7a.

Since except at initial transients the performances look similar, Figures 5 and 6 display respectively the evolution of respectively the angle of attack, the flight path angle, the elevator deflection and the throttle setting during the whole manoeuvre. 
Since the angle of attack remains in a safe domain and the considered longitudinal inputs remain by far unsaturated this demonstrates the feasibility of the manoeuvre.

Figure 7A and Figure 7B show airspeed and time tracking performances in two cases. The first one considers a delay situation for an aircraft according to a reference time table where the aircraft maintains its airspeed at $V_{M O}$ until it compensates the initial delay. In the second situation the aircraft is initially in advance with respect to the planned time table and in this case the speed controller sets its airspeed to the minimum allowable speed until the time tracking error is eliminated.

\section{Simulation results in the presence of wind}

Here a tailwind with a mean value of $12 \mathrm{~m} / \mathrm{s}$ has been considered. Figure 8 provide an example of realization of such wind.

Since in this study the problem of the online estimation of the wind components has not been tackled, it has been supposed merely that the wind estimator will be similar to a first order filter with a time constant equal to $0,35 \mathrm{~s}$ in one case (time NLI guidance) and with a space constant equal to $28 \mathrm{~m}$ in the other case (space NLI guidance). Then the filtered values of these wind components have been fed to the respective NLI guidance control laws.

Figure 9A and Figure 9B display altitude, airspeed and time tracking performances in the presence of the wind when the actual time table is late and in advance situations according to the reference time table, respectively. It appears that the proposed control technique (space-based NLI) keeps its performances shown in the sub-section above.

\section{Conclusion}

In this paper a new longitudinal guidance scheme for transportation aircraft has been proposed. The main objective here has been to improve the tracking accuracy performance of the guidance along a desired longitudinal trajectory referenced in a spatial frame. This has led to the development of a new representation of longitudinal flight dynamics where the independent variable is ground distance to a reference point. The nonlinear inverse control technique has been applied in this context so that tracking errors follow independent and asymptotically stable spatial dynamics around the desired trajectories. It has been shown also that a similar tracking objective expressed in the time frame cannot be equivalent when the desired airspeed changes as it is generally the case along climb and approach for landing.

Tracking performances obtained from spatial and time NLI guidance have been compared through a simulation study considering a descent maneuver of a transportation aircraft in wind and no wind conditions. It appears already that the proposed approach results in improved tracking performances as well as in an enhanced track predictability.

To get applicability this new guidance approach still should overcome important challenges related mainly with navigation and online wind estimation performances. Then an improved integration of on board flight path optimization functions including the consideration of neighbouring traffic and the guidance function will become possible.

\section{References}

[1] http://www.sesarju.eu/programme/highlights/i-4dflight.

[2] De Smedt David, Thomas Putz, October 25-29, 2009, Flight Simulations Using Time Control With Different Levels of Flight Guidance, Orlando, Florida, USA, IEEE/AIAA 28th Digital Avionics Systems Conference, pp. 2.C.5-1-2.C.5-15.

[3] Teutsch Jurgen, Eric offman, 2004, Aircraft in the Future ATM System-Exploiting the 4D Aircraft Trajectory, USA, IEEE/AIAA 23rd Digital Avionics Systems Conference, pp. 3.B.2-1-3.B.2-21.

[4] Pappas. G, C. Tomlin, J. Lygeros, D. Godbole and S. Sastry, December, 1997, A Next Generation Architecture for Air Traffic Management Systems, San Diego, California, USA, IEEE Proceeding of the 36th Conference on Decision and Control, pp. 24052411.

[5] Bernd Korn, Alexander Kuenz, 2006, 4D FMS for Increasing Efficiency of TMA Operations, USA, IEEE/AIAA 25th Digital Avionics Systems Conference, pp. 1E4-1-1E4-8.

[6] Shih-Yih Young, Real-Time 4-D Trajectory Planning for RNP Flight Operations, IEEE Integrated 
communications, Navigation and Surveillance Conference, pp. 1-9, 2009.

[7] Mayte Cano, Pablo Sanchez-Escalonilla and Manuel. M. Dorado, 2007, Complexity Analysis in the Next Generation of Air Traffic Management System, Dallas, Texas, USA, IEEE/AIAA 26th Digital Avionics Systems Conference, pp. 3.D.4-13.D.4-9.

[8] Miele A, et al, 1986, Guidance Strategies for Near-Optimum Takeoff Performance in Wind Shear, Journal of Optimization Theory and Applications, Vol. 50, No. 1.

[9] Miele A, et al, 1986, Optimization and Gamma/Theta Guidance of Flight Trajectories in a Windshear, London, Presented at the 15th ICAS Congress.

[10] Miele A, et al, 1990, Optimal Trajectories and Guidance Trajectories for Aircraft Flight Through Windshears, Honolulu, Hawaii, Proceedings of the 29th Conference on Decision and Control, , pp. 737746.

[11] Psiaki M.L. and R.F. Stengel, 1985, Analysis of Aircraft Control Strategies for Microburst Encounter, Journal of Guidance, Control, and Dynamics, Vol. 8, No. 5, pp. 553-559.

[12] Psiaki M.L. and K. Park, 1992, Thrust Laws for Microburst Wind Shear Penetration, Journal of Guidance, Control, and Dynamics, Vol. 15, No. 4.

[13] Singh S.N. and W.J. Rugh, 1972, Decoupling in a Class of Nonlinear Systems by State Feedback, ASME Journal of Dynamic Systems, Measurement, and Control, Series G, Vol. 94, pp. 323-329.

[14] Stengel, R.F, 1993, Toward Intelligent Flight Control, IEEE Trans. On Systems, Man, and Cybernetics, Vol. 23, No. 6, pp. 1699-1717.

[15] Sandeep S. Mulgund and Robert F. Stengel, January 1996, Optimal Nonlinear Estimation for Aircraft Flight Control in Wind Shear, Automatica, Vol.32, No. 1.

[16] Psiaki M.L, 1987, Control of Flight Through Microburst Wind Shear Using Deterministic Trajectory Optimization, Ph.D. Thesis, Department of Mechanical and Aerospace Engineering, Princeton University, Report No. 1787-T.

[17] Bouadi. H and F. Mora-Camino, May 17-18, 2012, Space-Based Nonlinear Dynamic Inversion Control for Aircraft Continuous Descent Approach, Madrid, Spain, IEEE Evolving and Adaptive Intelligent Systems Conference, pp. 164-169.

[18] Bouadi. H and F. Mora-Camino, August 13-16, 2012, Aircraft Trajectory Tracking by Nonlinear Spatial Inversion, Accepted in AIAA Guidance, Navigation and Control Conference, Minneapolis, Minnesota, USA.

[19] Etkin B, 1985, Dynamics of Atmospheric Flight, New York, John Wiley and Sons, Inc.

[20] Frost W, Bowles. R, 1984, Wind Shear Terms in the Equations of Aircraft Motion, Journal of Aircraft, Vol. 21, No.11, pp. 866-872.

[21] Campbell C. W, May 1984, A Spatial Model of Wind Shear and Turbulence for Flight Simulation, Tech. Rep. TP-2313, NASA George C. Marshall Space Flight Centre, Alabama 35812.

[22] Isidori A, Nonlinear Control Systems, SpringerVerlag, Berlin.

[23] Magni J-F. et al, Robust Flight Control, A Design Challenge, Springer-Verlag, London.

[24] I.J.-J. Slotine and L. Weiping, 1991, Applied Nonlinear Control, Prentice Hall, Upper Saddle River, NJ.

\section{Email Addresses}

Hakim Bouadi: hakimbouadi@yahoo.fr

$$
\text { Hakim.Bouadi@enac.fr }
$$

Félix Mora-Camino: moracamino@hotmail.fr Félix.Mora@enac.fr

Daniel Choukroun : D.Choukroun@tudelft.nl

31th Digital Avionics Systems Conference October 14-18, 2012 

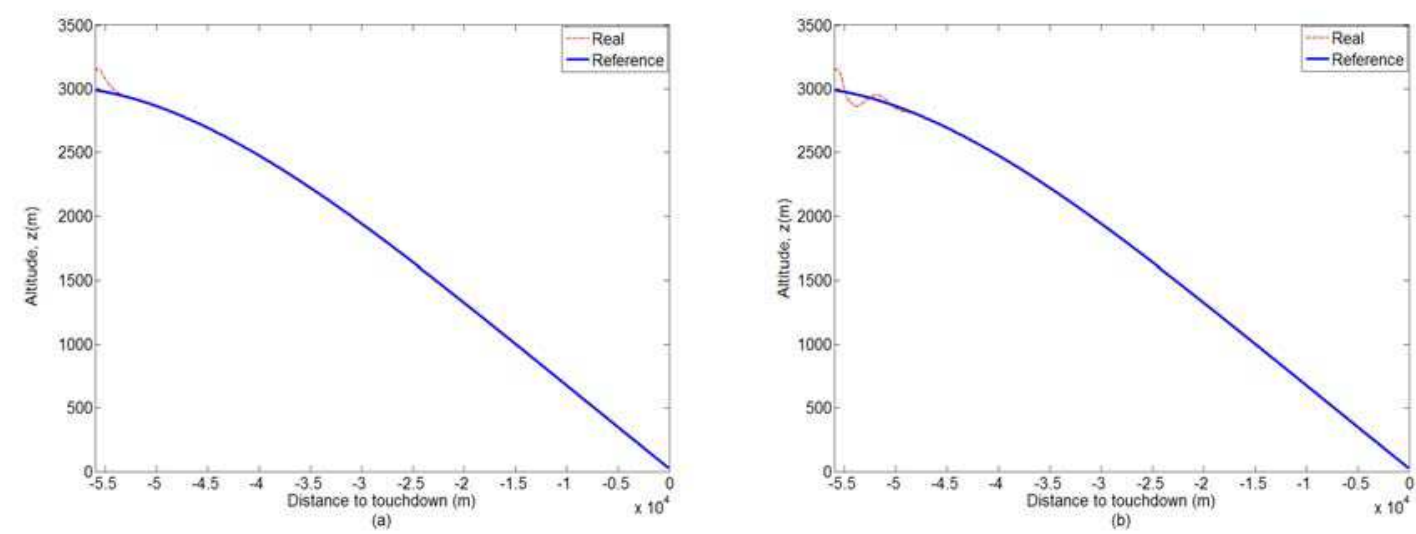

Figure 2. Desired Altitude Trajectory Tracking Performance by Space NLI (a) and Time NLI (b), Respectively. (No Wind).
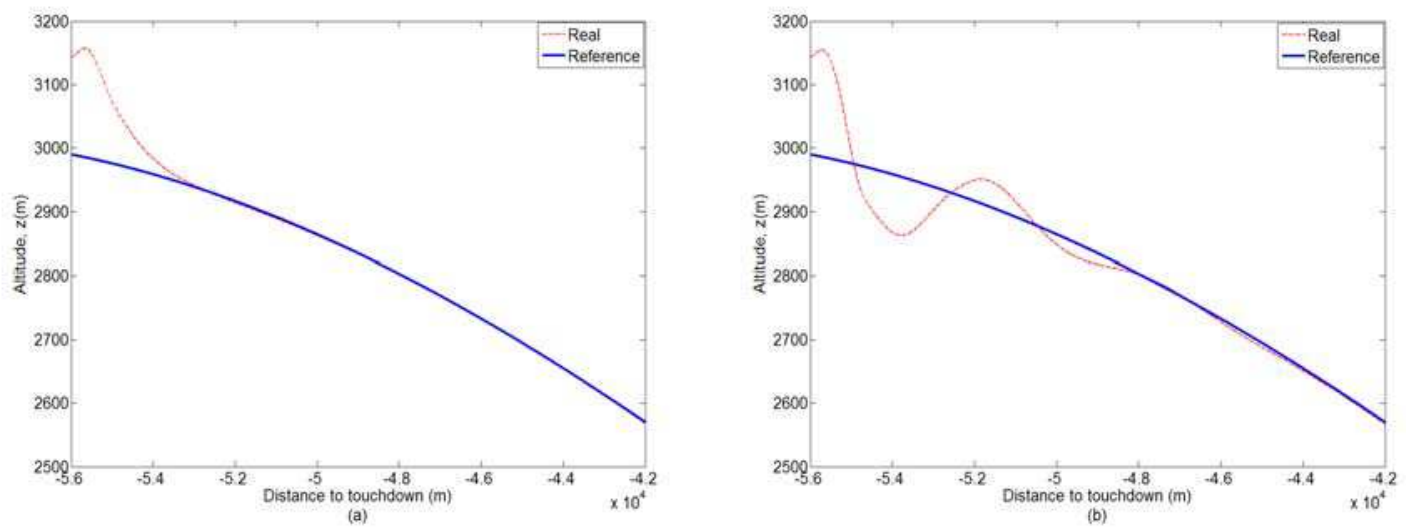

Figure 3. Initial Altitude Tracking by Space NLI (a) and Time NLI (b), (No Wind).
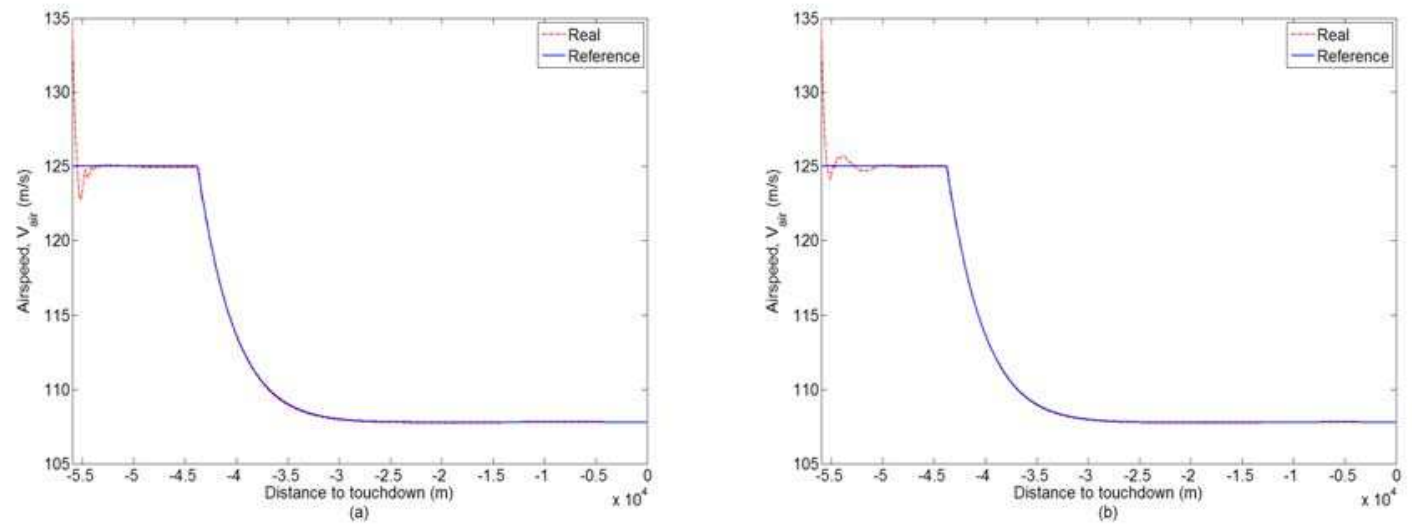

Fig 4. Desired Airspeed Profile Tracking Performance by Space NLI (a) and Time NLI (b), Respectively. (No Wind). 

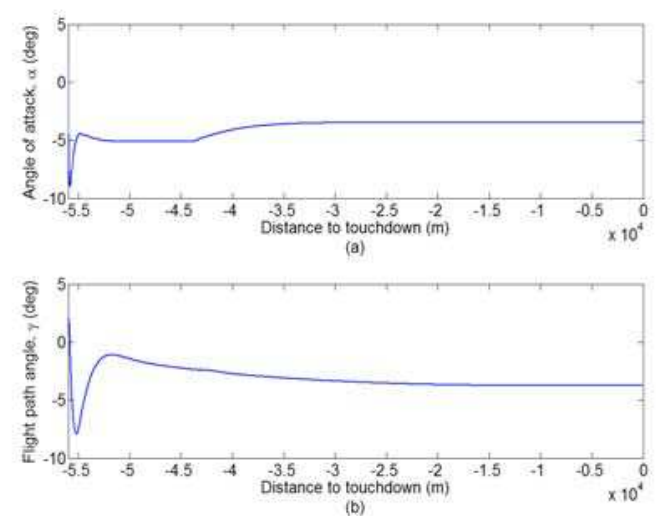
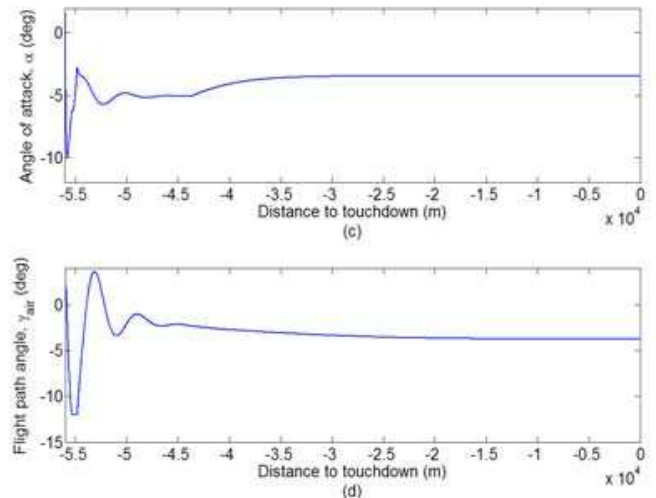

Fig 5. Angle of Attack and Flight Path Angle Evolution with Space NLI (a,b) and with Time NLI (c,d), Respectively. (No Wind).
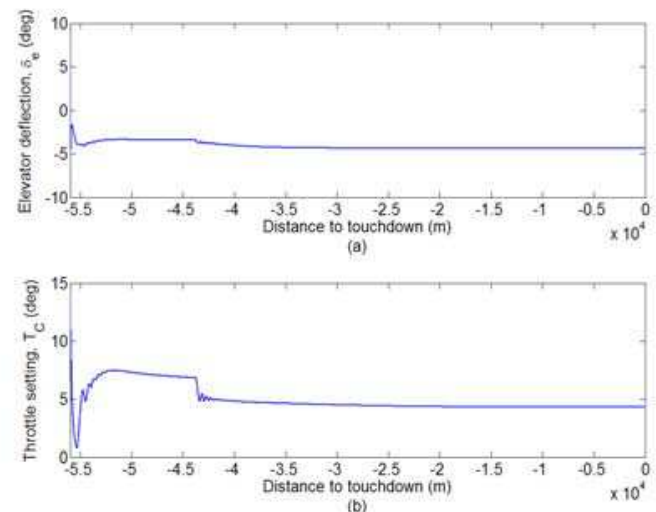
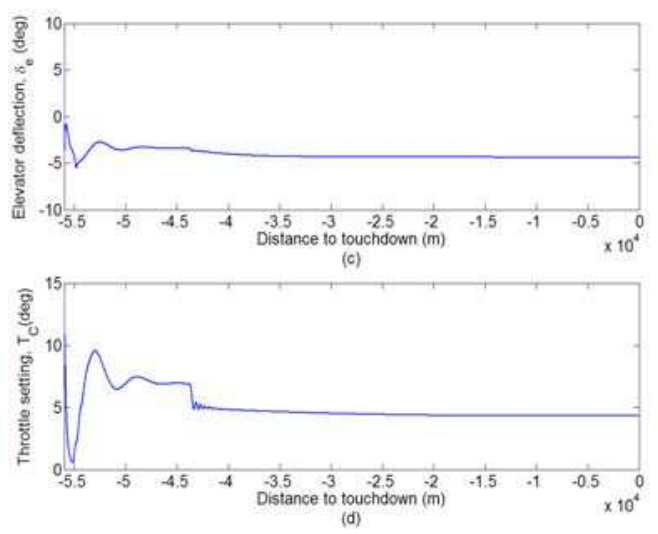

Fig 6. Control Inputs Evolution with Space NLI (a,b) and with Time NLI (c,d), Respectively. (No Wind).

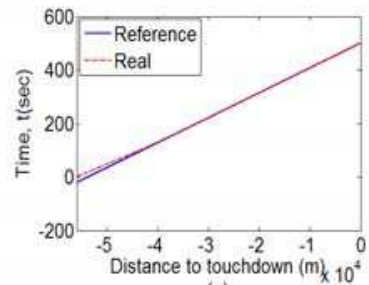

(a)

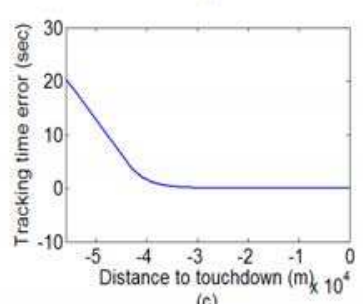

(c)
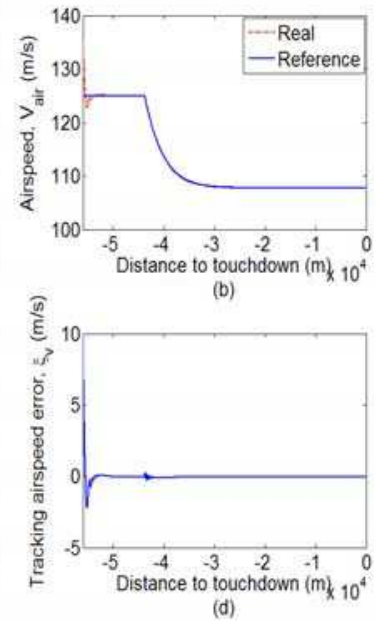

Fig 7.A Delayed initial situation and recover. 

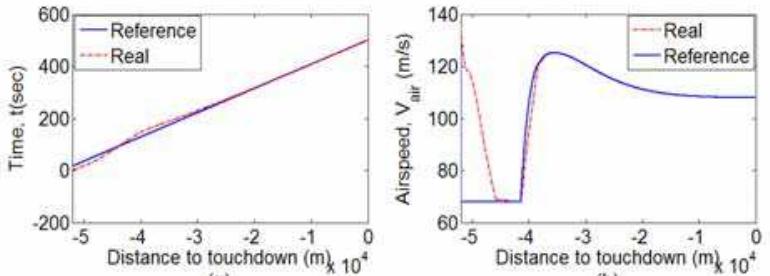

(a)
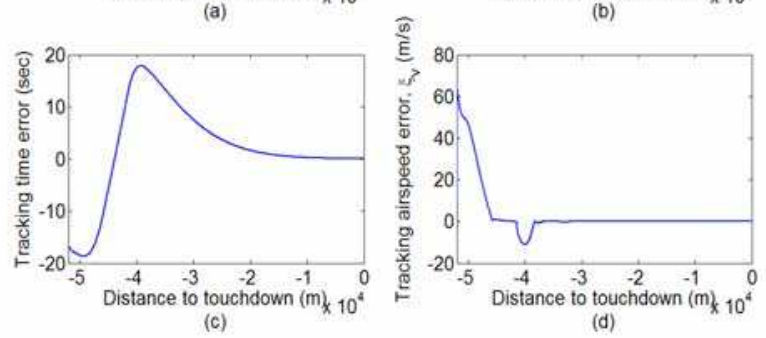

Fig 7.B Advanced initial situation and recover.
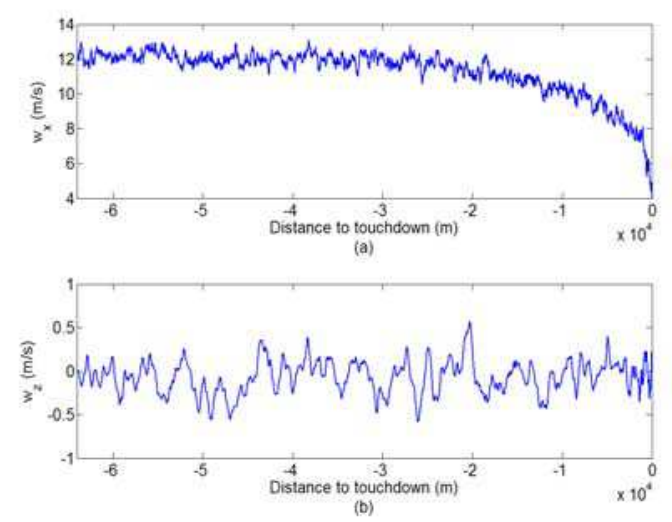

Fig 8. Example of realization of wind components. 


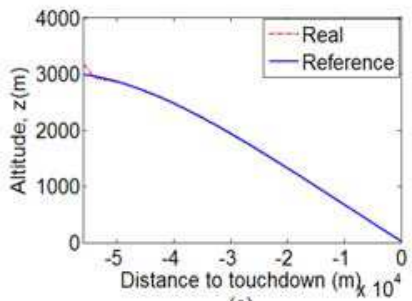

(a)

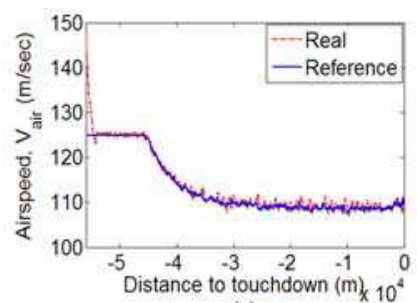

(c)

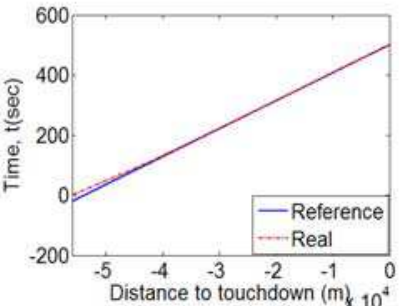

(b)

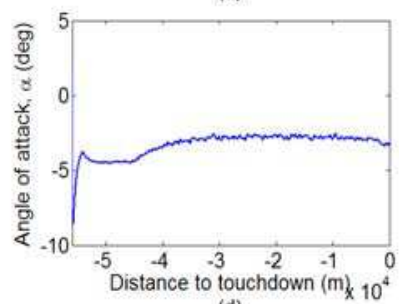

Fig 9.A Delayed initial situation and recover with wind.
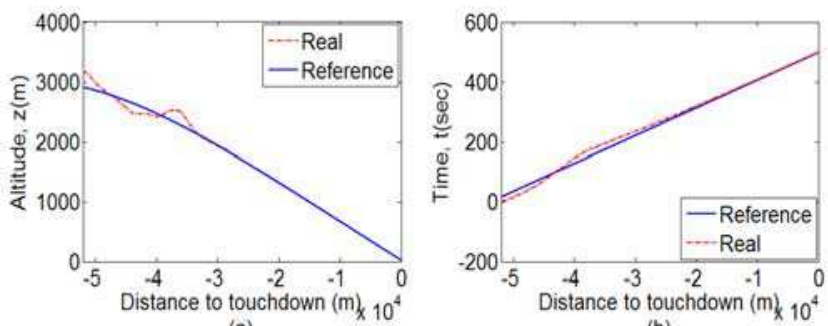

(a)

(b)

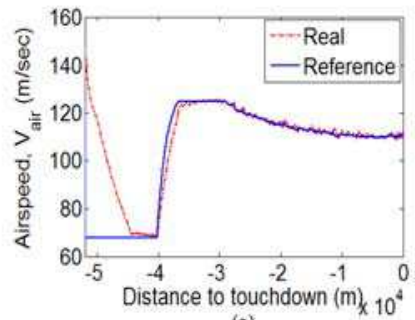

(c)

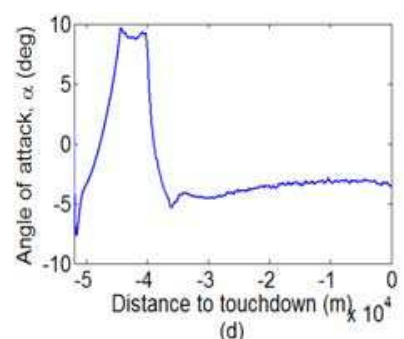

(d)

Fig 9.B Advanced initial situation and recover with wind. 